\title{
Case Report and Review of the Literature
}

\section{Situs Inversus Totalis and Sickle Cell Anemia: Case Report and Review of Literature}

\author{
Daniela de Oliveira Werneck Rodrigues ${ }^{1 *}$, Olivia Franco dos Santos ${ }^{2}$, Renato Lourenço de Medeiros ${ }^{3}$, Augusto Cézar \\ Apolinário dos Santos ${ }^{4}$, Rodrigo De Martin Almeida ${ }^{3}$, Jordana Alicia Silveira Lopes ${ }^{2}$, Thais Sette Espósito ${ }^{4}$, Jessica \\ Diniz Rezende ${ }^{4}$ and Tassia Mariana Moreira da Paz ${ }^{4}$ \\ ${ }^{1}$ Fundação Hemominas, Brazil \\ ${ }^{2}$ Universidade Federal de Juiz de Fora, Brazil \\ ${ }^{3}$ Faculdade de Ciências Médicas e da Saúde de Juiz de Fora, Brazil \\ ${ }^{4}$ Centro Universitário Presidente Antônio Carlos, Faculdade de Medicina Juiz de Fora, Brazil
}

\begin{tabular}{l} 
A R T I C L E I N F O \\
\hline Article history: \\
Received: 5 August, 2020 \\
Accepted: 18 August, 2020 \\
Published: 27 August, 2020 \\
Keywords: \\
Situs inversus \\
dextrocardia \\
sickle cell anemia
\end{tabular}

\begin{abstract}
A B S T R ACT
Background: Situs inversus totalis (SIT) is a rare, autosomal recessive congenital variation, in which the organs of the chest and abdomen are in a mirrored or reversed position in relation to the usual topography. The incidence of SIT in the general population is low and range of 1 in 8,000 to 1 in 25,000, with the majority of people affected being asymptomatic. Sickle Cell Anemia (SCA), however, is a genetic, monogenic, recessive disease, has a high prevalence in Brazil, with an estimate of 1: 1,350 live births.

Case Report and Methods: The authors report a rare case of SIT in a male child with SCA identified through neonatal screening. The patient's clinical data were extracted from medical records. The diagnosis of SIT was suspected in the pediatric consultation, after altered cardiac auscultation. Screening tests were performed to identify other somatic malformations.

Discussion: SIT is a rare and benign condition, with late and incidental diagnosis in most cases. SCA is a disease diagnosed through neonatal screening with a well-defined multidisciplinary team. In this patient, it was observed that specialized consultations in a reference service for genetic diseases led to early diagnosis of SIT. The importance of this case report is due to the rarity of SIT and the lack of description in the literature of SIT associated with SCA.
\end{abstract}

Introduction

Situs solitus is the name of the condition in which the body's organs are in their normal arrangement. Situs Inversus Totalis (SIT) is a rare condition, in which the organs are mirrored or inverted in relation to the usual topography. The incidence of dextrocardia associated with situs inversus in the population is $1: 10,000$ and the prevalence of SIT is between 1 in 25,000 and 1 in $8,000[1,2]$. There is a risk of 3 to $5 \%$ of patients with SIT to have congenital heart diseases, most of which are transposition of the great vessels. Another condition associated with SIT in $20 \%$ of cases is Kartagener Syndrome, which is characterized by the presence of bronchiectasis and sinusitis as a consequence of a congenital dysfunction of ciliary motility [2]. The detection of SIT in many cases is accidental and most patients live healthy and normally. However, there are some anatomical complications, which can lead to classic clinical signs of various diseases on the opposite side [3].

Sickle Cell Anemia (SCA), on the other hand, is a recessive genetic multisystem disease that is present worldwide. It is caused by the mutation in the sixth codon of chromosome 11, which promotes the replacement of glutamic acid by valine, in the $\beta$-globin gene, generating hemoglobin S (HbS)-characteristic of SCA. The homozygous genotype

*Correspondence to: Daniela de Oliveira Werneck Rodrigues, Fundação Hemominas Minas Gerais, Rua Barão de Cataguases, Juiz de Fora-MG, Brazil; Tel: +5532999796484, +553232573126; Fax: 3232573100; E-mail: danielawerneckhemato@hotmail.com,daniela.werneck@hemominas.mg.gov.br 
shows severe manifestations of the disease and contains $\mathrm{HbS}$ rates between $70 \%$ and $98 \%[4,5]$. The prevalence in Brazil is high, constituting the most common monogenic hereditary disease in the country. The estimated annual number of affected babies in Brazil is between 25,000 and 30,000, in North America it is 2,600 and in Europe $1,300[5,6]$. It is estimated that 230,000 children born in Sub-Saharan Africa are affected by the disease, corresponding to $80 \%$ of the global prevalence. The pathophysiology of the disease is summarized in the $\mathrm{HbS}$ intolerance to hypoxia, a situation that causes the sickling of red blood cells. After this transformation, red blood cells become inflexible, undergoing hemolysis and may cause anemia or even the obstruction of smaller blood vessels and organ damage $[5,7,8]$.

The authors relate a case of SIT associated with SCA, the importance of this case report is due to the rarity of SIT and the lack of description in the literature.

\section{Case Report}

The authors reported a case of a male child, born on January 1, 2004 in Juiz de Fora-Minas Gerais, Brazil, with a normal gestational history and birth through vaginal delivery without complications. The diagnosis of SCA was through neonatal screening using the isoelectric focusing for hemoglobin identification test, the study of haplotypes of the beta globin chain identified Bantu/Benin and the research for the coexistence of Alpha-Thalassemia $\left(\alpha^{3.7}\right)$ showed the deletion of 01 gene. The patient is from the A+ blood group and has been undergoing periodic hematological monitoring since March 2004, according to the protocol for comprehensive care for patients with sickle cell disease. The manual provides for multisystem evaluation from the clinical, laboratory and imaging exams point of view [9]. The diagnosis of SIT was early, in childhood, in March/2004, after the detection of abnormalities in cardiac auscultation in childcare.

A chest X-ray revealed heart and stomach gas on the right side (Figure 1). A conventional transthoracic echocardiogram revealed dextrocardia without another abnormalities (Figure 2). A computerized tomography of the abdomen was performed and showed the liver on the left side, spleen and stomach on the right side. No other congenital malformations were found (Figure 3). Currently, the patient is 16 years old and under periodic systematic control at the Hematology and Cardiology services.

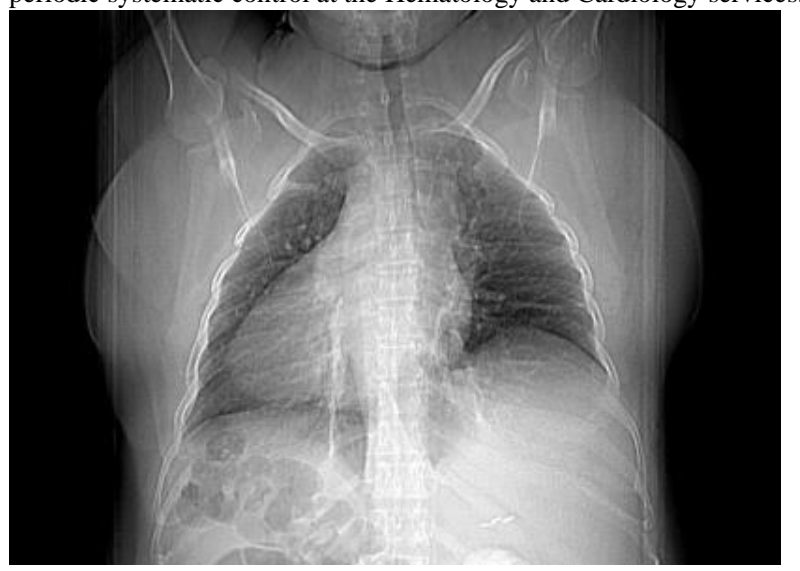

Figure 1: AP chest radiograph demonstrates dextrocardia. The cardiac apex and stomach gas are right-sided. The splenic shadow is in the right upper quadrant.

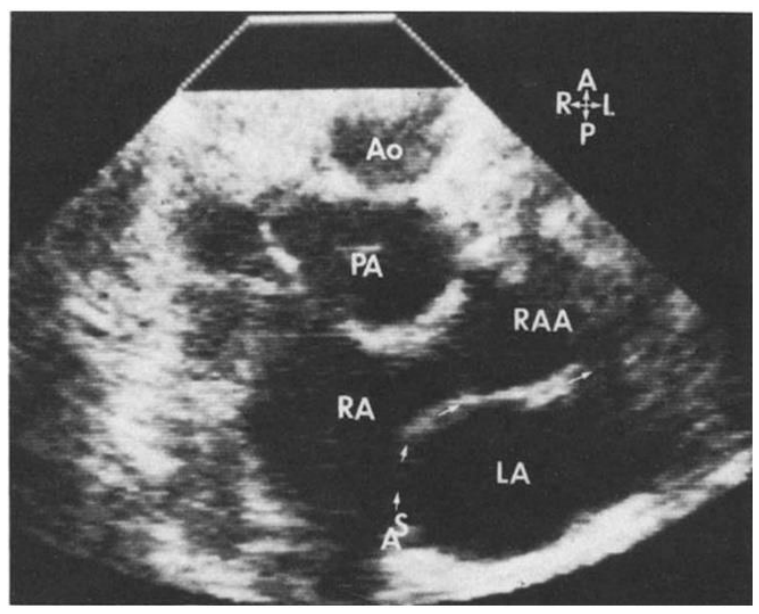

Figure 2: Echocardiogram revealing dextrocardia. Ao: Aorta; PA: Pulmonary Artery; RA: Right Atrium; RAA: Right Aortic Arc; LA: Left Atrium.

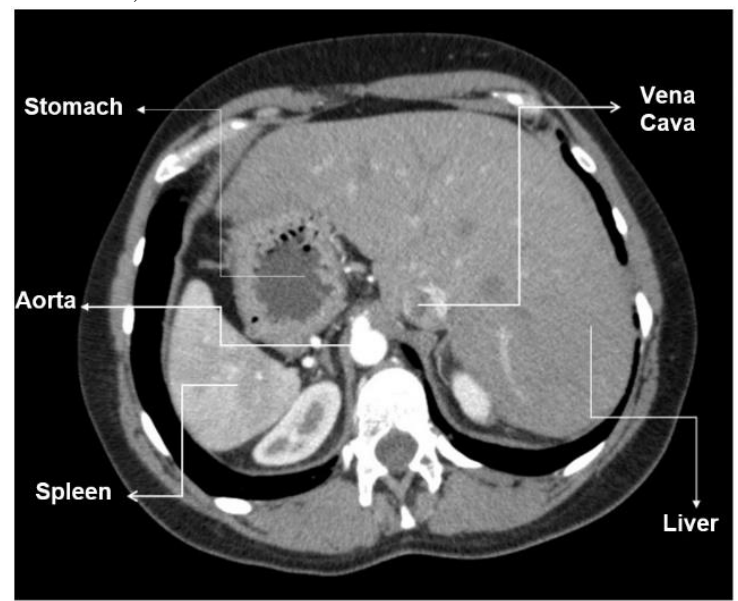

Figure 3: Computed tomography revealing stomach, aorta and spleen on the right side, vena cava and liver on the left side.

\section{Discussion}

The condition of SIT is rare and sometimes without clinical manifestations, having a late and incidental diagnosis in most of the cases. This entity is the mirror image of situs solitus. Situs inversus can be subdivided into SIT and situs inversus with levocardia. Regarding anatomy, the cardiac apex, spleen, stomach, jejunum, descending colon, and aorta are right-sided structures. The right lung is bilobed and the left lung is trilobed. The liver, gallbladder, ligament of Treitz, ileum, ascending colon, and inferior vena cava are left-sided structures [10-15]. Most individuals with situs inversus have congenital heart disease, while the incidence of this comorbidity with SIT is low, ranging from $2 \%$ to $5 \%[10,11,13,15]$. For diagnosis, chest radiography, ultrasonography, echocardiography, computed tomography, or magnetic resonance imaging may be ordered, evaluating the positions of the anatomical structures already mentioned [15]. In 2020, Chen et al. published a study to assess the spectrum and prevalence of comorbidities in SIT. The most associated condition were congenital heart defects. Despite that, in the group of 155 children, none had SCA similar to this report [16].

Shogan et al. presented the case of situs inversus totalis in a 22-monthold symptomatic infant, presented with cyanosis, cardiac malformation and severe pulmonary stenosis [17]. Different from this, our patient was 
diagnosed shortly after birth due to neonatal screening, without symptoms and without other anatomical malformations, however, with SCA. In comparison, SCA is a very prevalent disease that depends on early diagnosis in order to provide specialized treatment, which aims to increase patient's expectation and quality of life. In Brazil, since 2001, a neonatal screening program has been established that included the early identification of SCA. After diagnosis, patients are referred to the nearest blood center, a reference in treatment, to receive medications, vaccines and important guidance [9].

\section{Conclusion}

SIT is a rare entity diagnosed accidentally during radiologic exams, considering that most patients are asymptomatic. Currently, SCA is detected early by neonatal screening. The relevance of this case report is the description of the existence of 2 concomitant genetic alterations, without a previous description in the medical literature.

\section{Acknowledgements}

The authors would like to thank the patient who allowed his history to be published.

\section{Conflicts of Interest}

None.

\section{REFERENCES}

1. Luiz Flávio Galvão Gonçalves, Fernanda Maria Silveira Souto, Fernanda Nascimento Faro, Rodrigo de Castro Mendonça, Joselina Luzia Menezes Oliveira et al. (2013) Dextrocardia com Situs Inversus associada à cardiomiopatia não dilatada. Arq Bras Cardiol 101: e33e36. [Crossref]

2. Lucia Bartoloni, Jean Louis Blouin, Yanzhen Pan, Corinne Gehrig, Amit K Maiti et al. (2002) Mutations in the DNAH11 (axonemal heavy chain dynein type 11) gene cause one form of situs inversus totalis and most likely primary ciliary dyskinesia. Proc Natl Acad Sci U S A 99: 10282-10286. [Crossref]

3. Vijay Bhaskar Lakshman, Swaroop Revannasiddaiah, Ravindra Ganganna (2013) Situs inversus totalis discovered incidentally at the age of 84 years. BMJ Case Rep 2013: bcr2013008611. [Crossref]
4. Sajjad M Yousafzai, Murat Ugurlucan, Omar A Al Radhwan, Amal L Al Otaibi, Charles C Canver (2010) Open Heart Surgery in Patients with Sickle Cell Hemoglobinopathy. Circulation 121: 14-19. [Crossref]

5. David C Rees, Thomas N Williams, Mark T Gladwin (2010) Sickle Cell Disease. Lancet 376: 2018-2031. [Crossref]

6. Rodolfo D Cançado, Joice A Jesus (2007) A doença falciforme no Brasil. Rev Bras Hematol Hemoter 29: 204-206.

7. Jaíne B Stypulkowski, Vanusa Manfredin (2010) Alterações hemostáticas em pacientes com doença falciforme. Rev Bras Hematol Hemoter 32: 56-62.

8. Mario Sant'Anna Santoro, Haroldo José de Matos, Delaine Fidlarczyk (2011) Emergency care necessity for sickle cell disease patients at Rio de Janeiro State Coordinating Blood Bank. Rev Bras Hematol Hemoter 33: 115-119. [Crossref]

9. Brasil (2012) Ministério da Saude. Secretaria de Atenção à Saúde. Manual de condutas básicas na doença falciforme. Brasilia, DF.

10. Ann S Fulcher, Mary Ann Turner (2002) Abdominal manifestations of situs anomalies in adults. Radiographics 22: 1439-1456. [Crossref]

11. I L Tonkin, A K Tonkin (1982) Visceroatrial situs abnormalities: sonographic and computed tomographic appearance. AJR Am J Roentgenol 138: 509-515. [Crossref]

12. M Hernanz Schulman, M M Ambrosino, N B Genieser, D Friedman, H Banner et al. (1990) Pictorial essay. Current evaluation of the patient with abnormal visceroatrial situs. AJR Am J Roentgenol 154: 797-802. [Crossref]

13. Pierre D Maldjian, Muhamed Saric (2007) Approach to dextrocardia in adults: review. AJR Am J Roentgenol 188: S39-S49. [Crossref]

14. Hyun Woo Goo, In Sook Park, Jae Kon Ko, Yong Hwue Kim, Dong Man Seo et al. (2003) CT of congenital heart disease: normal anatomy and typical pathologic conditions. Radiographics 23: S147-S165 [Crossref]

15. K E Applegate, M J Goske, G Pierce, D Murphy (1999) Situs revisited: imaging of the heterotaxy syndrome. Radiographics 19: 837-852. [Crossref]

16. Weicheng Chen, Zhuoyao Guo, Liling Qian, Libo Wang (2020) Comorbidities in situs inversus totalis: A hospital-based study. Birth Defects Res 112: 418-426. [Crossref]

17. CPT Paul J Shogan, MC USAt, Col Les Folio, Usaf MC SFS (Ret.) T (2011) Situs Inversus Totalis. Military Med 7: 840. 